Article

\title{
Application of Time Series Models in Business Research: Correlation, Association, Causation
}

\author{
Zabihollah Rezaee $^{1, * \mathbb{C}}$, Sara Aliabadi ${ }^{2}$, Alireza Dorestani ${ }^{2}$ and Nick J. Rezaee ${ }^{3}$ \\ 1 School of Accountancy, Fogelman College of Business and Economics, The University of Memphis, \\ Memphis, TN 38152, USA \\ 2 Department of Accounting, Business Law and Finance, College of Business and Management, \\ Northeastern Illinois University, Chicago, IL 60625, USA; S-Aliabadi@neiu.edu (S.A.); \\ A-Dorestani@neiu.edu (A.D.) \\ 3 Department of Mathematics, University of California Santa Cruse, Santa Cruz, CA 95064, USA; \\ nrezaee@ucsc.edu \\ * Correspondence: zrezaee@memphis.edu
}

Received: 13 May 2020; Accepted: 10 June 2020; Published: 12 June 2020

\begin{abstract}
Time series models are used to determine relationships, spot patterns, and detect abnormalities and irregularities among data. We explore the application of time series analyses in business research by discussing the differences among correlation, association, and Granger causality and providing insight into their proper use in the sustainability literature. In statistics, two correlation coefficients are typically calculated. The first one is the Pearson correlation coefficient and the second is the Spearman correlation coefficient. In the commonly used correlation analysis (the Pearson and the Spearman correlation coefficients), the focus is primarily on the changes in two variables regardless of the effects of other variables. On the contrary, in association analyses, the researcher examines the relationship between two variables while holding the effects of other related variables constant (ceteris paribus). In the study of the causation, or the cause-effect relationship between two variables, researchers are concerned about the effect of variable $\mathrm{X}$ on variable $\mathrm{Y}$. The difficulty of achieving the third condition of causation is believed to be the main reason that in business literature causations are rarely used. The difficulty of achieving a causal relationship between two variables has moved researchers toward a special form of causation called "Granger causality". We offer practical examples for correlation, association, causation, and the Granger causality and discuss their main differences and show how the use of a linear regression is inappropriate when the true relationship is non-linear. Finally, we discuss the policy, practical, and educational implications of our study.
\end{abstract}

Keywords: time series; Granger causality; business sustainability

\section{Introduction}

Time series models are used in analyzing millions of transactions in spotting patterns, determining relationships, and detecting abnormalities and irregularities among dependent data. The emergence of business sustainability creates an opportunity to further examine the application of time series models using financial economic performance information and non-financial environmental, social, and governance (ESG) sustainability performance information. We address the application of time series models in business research by discussing the differences between correlation, association, and Granger causality and provide practical examples of their application in analyzing financial and non-financial sustainability data and their relationships. Time series analyses have traditionally been used in many disciplines such as finance, marketing, engineering, and medical sciences. In economics, finance, and marketing, the main use of time series analyses is forecasting. In marketing, the use of time 
series analyses is primarily focused on detecting the pattern of consumer buying habit to predict their future purchases. Time series models such as random walk, random walk with drift, and white noise are the most commonly used time series analyses in economics and finance. However, the use of time series analyses is uncommon in accounting and auditing professions, particularly in the sustainability literature. Thus, this study explores the use of time series analyses in examining the financial and non-financial dimensions of sustainability performance and its consequences for decision-making by all stakeholders.

Prior studies on sustainability-related research published in premier business and accounting journals conclude that, despite more than several decades of research and more than 100 sustainability-related empirical studies, the results are mixed regarding the link between sustainability performance and financial performance because of empirical model specifications [1,2]. Business sustainability is defined in the literature as a process of achieving financial economic sustainability to generate desired long-term returns on investment for shareholders while protecting interests of other stakeholders in achieving environmental, social, and governance (ESG) sustainability performance [2]. We argue that the mixed results of prior sustainability studies are triggered by using different periods, estimation methods, definition, and construction of related variables and, more importantly, the interpretation of results in terms of correlation, association, and causation. Because of these shortcomings and mixed results, we are motivated to study this topic and make an effort to add to the sustainability literature by investigating differences and interpretations of correlation, association, causation, and Granger causality. We present examples for correlation, association, causation, and the Granger causality, examine their main differences and illustrate how the use of a linear regression is inappropriate when the true relationship is non-linear. Finally, we discuss the policy, practical, and educational implications by showing how time series models can be efficiently and effectively applied in business sustainability, developing predictive models of managerial strategies, decisions and actions, evaluating the feasibility, cost efficiency and effectiveness of new rules, regulations, and using time series in data science algorithms to capture all relevant financial and non-financial information for decision-making.

The remainder of this paper is organized as follows: Section 2 presents institutional foundation, whereas Section 3 provides the literature review. Section 4 presents practical examples and implications of these examples are offered in Section 5. The last section concludes the paper.

\section{Institutional Foundation}

In econometrics textbooks the most commonly used representation is a structural equation model (SEM). This form of econometrics representation is so important that almost all econometrics textbooks start with discussions of SEM. As an example, prior studies [3] examine the effect of excise cigarette taxes on the extent of smoking by using the following simple linear regression model:

$$
Y=\beta X+\varepsilon
$$

In this equation, the dependent variable, $\mathrm{Y}$, is the extent of smoking, the independent variable, $\mathrm{X}$, is the excise cigarette tax and $\varepsilon$ is the entire error included in the model (e.g., errors of measurements, model mismedication). In this model, to estimate the $\beta$ coefficient (called the effect coefficient), it is critical that $X$ and $\varepsilon$ be independent of each other. The independence of $X$ from $\varepsilon$ is known as the exogeneity of $X$, or $X$ being an exogenous variable. Independent variables $(X)$ and error term must be independent of each other. In fact, the error term is the effects of all other variables that are not included in the model. The $X$ represents all variables that are included in the model. If $X$ and error term are not independent, then we will have serial correlation. Researchers argue that if all underlying assumptions of the SEM are maintained, then the model can answer all questions related to causal relationships [3]. 
Haavelmo [4] concludes that in the linear equation of $Y=\beta X+\varepsilon$, the $\beta X$ is the expected value of $Y$ given that we set the value of $X$ at $x$ or simply set $\beta x=E[Y \mid x]$, which is different from the conditional expectation [5]. Some studies argue that the above interpretation has been misunderstood or questioned by many econometricians [6]. For example, Goldberger [7] agrees with the interpretation that considers $\beta X$ to be the expected value of $Y$ given that $x$ is fixed, while Wermuth [8] disagrees and instead argues that $\beta \mathrm{X}$ is not $\mathrm{E}[\mathrm{Y} \mid \mathrm{X}]$.

The main difference between Goldberger [7] and Wermuth's [8] interpretations, in which econometrics textbooks fall, is whether the structural equations imply a causal meaning or not. Some econometrics textbooks posit that SEM equations represent causal relationships, while other textbooks posit that the SEM equations represent the joint probability distribution. These two points of view are the extreme points and most econometrics textbooks fall somewhere between these two.

Chen and Pearl [6] argue that the main source of confusion is the lack of a precise mathematical definition of casual relationship. They state that SEM equations are used for two different purposes: one is for predictive problems and the other one is for causal problems or policy decisions. In predictive problems, one seeks to answer the question of what the value of $Y$ will be given that we observe the value of $X$ to be $x$. In predictive problems, we can define $\beta$ by the expression of $\beta x=E[Y \mid d o(x)]$, but it is incorrect to define $\beta$ in the same way for casual relationship.

Another relevant concept is ceteris paribus. The concept of ceteris paribus is widely used in economics and is directly linked to causal relationships. In econometrics when we talk about the definition of demand, we state that when the price of a good rises, then the quantity demanded of that good will decrease, ceteris paribus, or holding other factors fixed. With the same notion when we hold all other variables fixed, or ceteris paribus, then any relationship between $Y$ and $X$, in $Y=\beta X+\varepsilon$ relationship, must be a causal relationship.

Another concept that is tied to causal relationship is the discussion of $X$ to be an exogenous variable. The exogeneity of $\mathrm{X}$ in a linear relationship between $\mathrm{Y}$ and $\mathrm{X}$ is held when $\mathrm{X}$ is independent of all other factors (variables) included in $\varepsilon$. For example, in a completely randomized process in which all participants are randomly assigned to either control or treatment group, independent of characteristics of the subjects, we can argue that $X$ is exogenous. This interpretation of the exogeneity of $\mathrm{X}$ is different from the alternative interpretation in which one defines $\beta \mathrm{X}$ as $\mathrm{E}[\mathrm{Y} \mid \mathrm{X}]$. In other words, if the researcher is only interested in a conditional expectation or prediction, then the causal relationship is of no importance. This argument is consistent with textbooks authored by Hill, Griffiths and Lim [9].

As discussed earlier, in the equation representing the relationship between $\mathrm{Y}$ and $\mathrm{X}$, it is necessary for $X$ to be exogenous and uncorrelated with $\varepsilon$ in order to estimate $\beta$ in the $Y=\beta X+\varepsilon$ relationship. In this equation, $\varepsilon$ is the effect of all other variables causing change in $Y$ that are not included in $X$. The $\beta$ represents the change in $Y$ when $X$ changes by one unit holding all other variables fixed, ceteris paribus. In addition, Chen and Pearl [6] argue that if we incorrectly consider $\beta X$ to be the expected value of $\mathrm{Y}$ given $\mathrm{X}$ or $\mathrm{E}[\mathrm{Y} \mid \mathrm{X}]$, then the statement of independence of $\mathrm{X}$ of $\varepsilon$ will be meaningless. In this context, the $\mathrm{E}[\mathrm{Y} \mid \mathrm{X}]$, is called the conditional expectation of $\mathrm{Y}$. If we are only interested in the conditional expectation, then any bias in the causal relationship can be ignored, and we can reliably use the regression equation for estimating $\alpha$, or the slope of the equation.

Furthermore, Chen and Pearl [6] argue that if, through randomization, we force the exogeneity to $X$, then we will not estimate the conditional expectation, but the interventional expectation. They added that conditional expectation and the interventional expectation are not the same and posit that, "by requiring that exogeneity be a default assumption of the model, we limit its application to trivial and uninteresting problems, providing no motivation to tackle more realistic problems" [6].

In short, we argue that in business research, researchers need to differentiate between correlation, association, causation, and Granger causality. Correlation is a statistical measure of the relationship between two variables ignoring the effects of other variables. Correlation measure ranges between -1 and +1 with -1 indicating a perfect negative correlation and +1 indicating a perfect positive correlation. No correlation is represented by close to zero correlation and approaches zero when 
the two variables are not linearly dependent. In calculating the correlation coefficient, no effort is made to control the effects of other related variables. However, in calculating the association measure, the researcher examines the relationship between two variables while holding the effects of all other related variables fixed. In other words, the association is represented by $\beta$ in the relationship between $Y$ and $X$, which indicates the extent of change in $Y$ when $X$ changes, holding the effects of all other variables unrelated to $X$ and $Y, \varepsilon$, fixed (ceteris paribus).

In the study of the causation, or the cause-effect relationship between two variables, researchers are concerned about the effect of $X$ on $Y$. In other words, in the presence of a causal relationship we posit that $X$ causes changes in $Y$. For causation between $X$ and $Y$ in the direction from $X$ to $Y$ (for $X$ to cause $\mathrm{Y}$ ) to hold, three conditions must be present: (1) $\mathrm{X}$ and $\mathrm{Y}$ must vary together, (2) X must occur before $Y$ and (3) no other variables must cause change in $Y$ (when the effects of these other variables are controlled). That is, the researcher should show that when $X$ does not change, then there will be no change in Y. We believe that condition (3) is the most difficult one to achieve. This difficulty is believed to be the main reason that causation is rarely used or used incorrectly in the business literature.

The difficulty of achieving a causal relationship between two variables moved researchers toward a special form of causation called "Granger causality." Granger [10] introduced, for the first time, a specific form of causation that later became known as "the Granger causality." He posits that if a variable Granger causes another variable, then we can use the past values of the first variable to predict the value of the second one beyond the effects of past values of the second variable.

The above discussions reveal that the strongest relationship between two variables is a causal relationship; however, when it is not possible to show a cause-effect relationship, then the next best relationship is the Granger causality relationship. Furthermore, most business researchers are interested in using a linear model to fit their data. Even though a linear model may be a good approximation to fit data, the use of a linear model is not appropriate in many cases, as we have shown below.

Taken together, the extant business literature examines the relationship between two variables, but in most cases, researchers do not properly differentiate between correlation, association, and causation, and in many cases the researchers use these terminologies interchangeably despite their major differences. Given the above discussions, this study is an attempt to show how the use of a linear relationship can be misleading in some cases and shows how sustainability research can extend beyond reporting only correlation and association between ESG sustainability performance and financial performance. In our study, by using practical examples, we show how the Granger causality test which is based on time series analyses can be incorporated into sustainability research.

\section{Literature Review}

A large body of the literature discusses the applications of econometrics tools such as correlation, association, and Granger causality. Correlation analysis is used in almost all studies that use regression equations to be sure that independent variables are not correlated with each other because high correlation between independent variables can result in a multicollinearity problem. The multicollinearity problem creates bias in the estimates of regression coefficients. Examples of correlation analyses can be found in prior studies [11-14]

Regression analysis is extensively used by researchers in different fields. For example, Francis and Mialon [15] examine the association between the duration of marriages and wedding expenses by conducting a survey of 3000 married individuals in the United States and regress wedding expenses (ceremonies and engagement rings) against marriage duration. Francis and Mialon [15] find a negative association between these two variables suggesting that when wedding expenses increase, duration of marriage decreases. Other studies examine the association between determinants of quality of marriage and its duration [16-20].

In the area of Granger causality, Cevher [21] posits that $X$ Granger causes $Y$ if $Y$ can be predicted by considering the past observations of both $X$ and $Y$. As an example, Cevher [21] argues that the extent of parents' expenditures on education for their children will result in the success of their children in 
the future, finding a positive association between spending on education and results of education. This type of relationship provides an example of classical Granger causality, and its validity can be tested when both variables (in a two-variable model) are stationary. When two variables are not stationary, but are associated in long run (meaning that they are cointegrated), then it is not possible to find a vector autocorrelation (VAR) model. In this instance, the classical Granger causality test is not appropriate. However, when at least one variable is not stationary, the Toda-Yamamota test can and should be used for the Granger causality test among variables [22].

There are two categories of Granger causality, classical Granger causality and modern (advanced) Granger causality analyses. In classical Granger causality, Cevher [21] posits that the pairwise Granger causality should be used when there is only one dependent variable and one independent variable. Therefore, in this type of Granger causality relationship, the researcher analyzes variables only two by two. On the contrary, in modern (advanced) Granger causality, there exist more than two variables and dependent and independent variables are not determined in advance. Dependent and independent variables in this type of Granger causality are determined by a tool called R Package. For a discussion of R package and its application in advanced (modern) Granger causality, the reader can refer to the Boelstraete and Rosseel [23] paper.

Granger causality can be either conditional or partial. Conditional Granger causality is used when the Granger causality from $X$ to $Y$ and $Z$ depends on other variables. When conditional Granger causality fails (that is, when exogenous variables are present), then prior research concludes that partial Granger causality should be applied [24]. Partial Granger causality takes into account the underlying relationship among all variables in a network. Finally, authors question the validity of a special type of Granger causality in neuroscience called the Granger-Geweke causality and concluded that Granger-Geweke may not be applicable without considering the critical components of the system [25]. These authors argue that the lack of attention to the critical components of the system model can lead to spurious results [25]. However, Barnett, Barrett and Seth [26] reject the above criticism and argue that this criticism is the result of a misconception, as well as an incomplete review of related literature. The next section provides several practical examples of using correlation, association, causation, and Granger causality.

\section{Theoretical Framework and Practical Examples}

\subsection{Correlation}

In statistics, two correlation coefficients are typically calculated. The first one is the Pearson correlation coefficient and the second one is the Spearman correlation coefficient. Another type of correlation is the rank correlation presented by Kendall [27], which can be applied when comparing two different rankings of the same set of variables and is more applicable in psychology than business research. The Pearson coefficient, or the Pearson product-moment correlation coefficient, is a measure of the linear relationship between two variables. The Pearson correlation coefficient ranges from -1 to +1 , with -1 represents perfect negative linear relationship, +1 represents perfect positive linear relationship and zero represents no correlation between two variables. The Pearson coefficient is used when two variables, $\mathrm{Y}$ and $\mathrm{X}$, are interval or ratio data. The formula used to calculate the Pearson correlation coefficient is:

$$
\rho X, Y=\frac{\operatorname{Cov}(X, Y)}{\sigma_{X} \sigma_{Y}}
$$

where:

$\rho X, Y=$ Pearson correlation coefficient;

$\operatorname{Cov}=$ Covariance; $\sigma_{X}=$ the standard deviation of $X$;

$\sigma_{Y}=$ the standard deviation of $Y$;

$\operatorname{Cov}(X, Y)=E\left[\left(X-\mu_{X}\right)\left(Y-\mu_{Y}\right)\right]$. 
The Pearson coefficient was first introduced by Kari Pearson [28] who obtain this idea from Francis Galton in the 1880s. The Spearman correlation coefficient, or the Spearman's rank-order correlation, is the nonparametric version of the Pearson linear correlation. The Spearman correlation coefficient measures the strength, as well as the direction, of relationship between ranked variables. The Spearman coefficient is used when variables are ordinal data. The formula for calculating the Spearman correlation coefficient is:

$$
\mathrm{S}=1-\frac{6 \sum d_{i}^{2}}{n\left(n^{2}-1\right)}
$$

where:

$\mathrm{S}=$ Spearman correlation coefficient;

$d_{i}=$ difference in paired orders;

$n=$ number of cases.

As an example of the linear correlation coefficient, we prepare descriptive statistics (Table 1) and calculate Pearson correlation coefficient (Table 2) between two variables, quarterly net income $(X)$ and stock price (Y), of General Motors (GM) from the first quarter of 1979 until the last quarter of 2016. The calculated Pearson linear correlation coefficients are shown in Table 2:

Table 1. Descriptive statistics.

\begin{tabular}{ccc}
\hline & Net Income & PRICE \\
\hline Mean & 806.2118 & 37.11997 \\
Median & 876.9500 & 36.33750 \\
Maximum & $127,140.0$ & 87.00000 \\
Minimum & $-38,963.00$ & 0.331000 \\
Std. Dev. & $11,190.71$ & 15.71062 \\
Skewness & 9.169656 & 0.153299 \\
Kurtosis & 109.4908 & 3.938673 \\
Jarque-Bera & $73,951.91$ & 6.175689 \\
Probability & 0.000000 & 0.045600 \\
Sum & $122,544.2$ & 5642.235 \\
Sum Sq. Dev. & $1.89 \times 10^{10}$ & $37,270.34$ \\
Observations & 152 & 152 \\
\hline
\end{tabular}

Table 2. Pearson correlation matrix.

\begin{tabular}{ccc}
\hline & Price $(\mathbf{Y})$ & Net Income $(\mathbf{X})$ \\
\hline Price $(\mathrm{Y})$ & 1.00000 & -0.08658 \\
Net Income $(\mathrm{X})$ & -0.08658 & 1.00000 \\
\hline
\end{tabular}

The above table shows that the stock price and quarterly net income of General Motors move in opposite directions. The $p$-value of -0.08658 is negative and considered marginally significant but not highly significant. As we discussed earlier, in calculating correlation coefficient we ignore the effects of other related variables. However, in the context of time series analysis, the partial correlation function (e.g., partial autocorrelation) can be used to describe the linear relationship between two variables [29].

The calculated Spearman or ranked correlation coefficient is shown in Table 3:

Table 3. Spearman correlation matrix.

\begin{tabular}{ccc}
\hline & Price $(\mathbf{Y})$ & Net Income $(\mathbf{X})$ \\
\hline Price $(\mathrm{Y})$ & 1.00000 & 0.25225 \\
Net Income $(\mathrm{X})$ & 0.25225 & 1.00000 \\
\hline
\end{tabular}


The above table shows that the stock price and quarterly net income of General Motors move in the same direction when we use the Spearman correlation coefficient.

\subsection{Associations}

In association analyses, a researcher examines the relationship between two variables while holding the effects of other related variables unchanged (ceteris paribus). Association is generally represented by the following equation:

$$
Y=\beta X+\varepsilon
$$

where:

$\mathrm{Y}=$ the dependent variable;

$\mathrm{X}=$ independent variable or variables;

$\beta=$ slope of the equation;

$\varepsilon=$ effects of all other variables that are not included in the equation.

In Equation (4), If $X$ is a variable $\beta$ is a single parameter (slope of the regression line and not slope of the equation) while if $X$ is a matrix (it contains more variables), then $\beta$ is a vector of parameters. The components of any regression equations, are dependent variable, independent variable, intercept, and slope. By saying "slope of equation", we refer to one of these components. Before running any association model, the researcher should conduct the unit root test to be sure variables do not have unit root. The reason for this test is to avoid the probability of having a spurious regression. Spurious regression occurs when two variables have a unit root (increasing overtime) and when we regress one against the other one, they show that they are associated with each other, when, in fact, they are not associated with each other and a third variable causes both of them to move in the same direction. In this situation, the researcher should regress the change in one variable against the change in the other one. After regressing these two changes and observing that they are associated with each other, we can conclude that these two variables are co-integrated or are associated with each other in long run. Table 4 shows the result of unit root tests for main variables (net income and price) that are used in our association model. The Augmented Dickey-Fuller test statistic indicates that we should reject the null hypothesis because there exists unit root [30].

Table 4. Augmented Dickey-Fuller test statistic.

\begin{tabular}{ccc}
\hline & t-Statistic & Prob. \\
\hline Price & -2.898704 & 0.0478 \\
Net Income & -13.33675 & 0.0000 \\
\hline
\end{tabular}

In the following, we examine the linear association between stock price and quarterly net income of General Motors (GM) by holding the effects of variables such as total assets, liabilities, cash, and short-term investment, and dividend fixed. That is, we are running the following linear regression model:

$$
\text { Price }=\beta_{0}+\beta_{1} \mathrm{NI}+\beta_{2} \mathrm{ASSET}+\beta_{3} \mathrm{LIABIL}+\beta_{4} \mathrm{CASH}+\beta_{5} \mathrm{DVD}
$$

where:

Price: stock price of GM at the end of the period;

NI: net income of GM for the period;

ASSET: total assets of GM at the end of the period;

LIABIL: total liabilities of GM at the end of the period;

CASH: total cash and short-term investment at the end of the period; 
DVD: dividend paid for the period.

The results of running the above model are shown in Table 5:

Table 5. Output of linear regression model (2).

\begin{tabular}{ccccc}
\hline \multicolumn{5}{c}{ Dependent Variable: PRICE } \\
\hline Variable & Coefficient & Std. Error & t-Statistic & Prob. \\
\hline Const. & 33.27471 & 2.913504 & 11.42086 & 0.0000 \\
NI & $3.91 \times 10^{-6}$ & $8.75 \times 10^{-5}$ & 0.044645 & 0.9645 \\
ASSET & 0.000160 & $4.49 \times 10^{-5}$ & 3.569371 & 0.0005 \\
LIABIL & $-7.02 \times 10^{-5}$ & $4.46 \times 10^{-5}$ & -1.573200 & 0.1182 \\
CASH_STI & -0.000895 & $9.63 \times 10^{-5}$ & -9.294673 & 0.0000 \\
DVD & 0.001628 & 0.001968 & 0.827111 & 0.4098 \\
R-squared & 0.513012 & Mean dependent var & 38.92902 \\
Adjusted R-squared & 0.493532 & S.D. dependent var & 15.92523 \\
S.E. of regression & 11.33344 & Akaike info criterion & 7.738111 \\
Sum squared resid & $16,055.85$ & Schwarz criterion & 7.869800 \\
Log likelihood & -500.8463 & Hannan-Quinn criter. & 7.791622 \\
F-statistic & 26.33593 & Durbin-Watson stat & 0.580953 \\
Prob(F-statistic) & 0.000000 & & \\
\hline
\end{tabular}

The above table shows that if we hold the effects of variables such as assets, liabilities, cash, and short-term investment and dividend fixed, then there will be no association between stock price and quarterly net income of GM $(0.05<p=0.9645)$. The same results hold when we examine the association between stock price and liabilities $(0.05<p=0.1182)$ or stock price and dividend $(0.05<p=0.4098)$. However, there is a significant positive association between stock price and total assets and stock price and cash and short-term investment when we hold the effects of other related variables fixed. As we mentioned before, association is an improvement over simple correlation relationship.

\subsection{Non-linear Model}

Further analysis of the above linear regression reveals that the relationship between net income and stock price of GM is not linear, so to come up with a non-linear model that better represents the relationship between these two variables, we have examined data using alternative models and come up with the following model, which is an autoregressive conditional heteroskedasticity (ARCH) model. The ARCH model is often used in finance to provide a systematic framework for volatility modeling when the mean-corrected of the variable of interest (e.g., stock price, net income in our study) is serially uncorrelated but dependent, and the dependence can be described by the lag values [31]. We use an autoregressive-moving-average (ARMA) model in analyzing data from the first quarter of 1979 to the last quarter of 2016. An ARMA model combines a moving average process with a linear difference equation.

$$
y_{t}=\beta_{0}+\beta_{1} y_{t-1}+\beta_{2} y_{t-3}+\beta_{3} x_{t}+\beta_{4} x_{t-1}+\beta_{5} x_{t-2}+\beta_{6} x_{t-3}
$$

where:

$y_{t}:$ price of GM stock at the end of quarter $t$;

$y_{t-1}$ : price of GM stock at the end of quarter $t-1$;

$y_{t-3}$ : price of GM stock at the end of quarter $t-3$;

$x_{t}$ : net income of GM during quarter $t$;

$x_{t-1}$ : net income of GM during quarter $t-1$;

$x_{t-2}$ : net income of GM during quarter $t-2$;

$x_{t-3}$ : net income of GM during quarter $t-3$. 
The results of running Model (6) are shown in Table 6:

Table 6. Output of non-linear model (6).

\begin{tabular}{ccccc}
\hline \multicolumn{5}{c}{ Dependent Variable is $\mathbf{y}_{\mathbf{t}}$} \\
\hline Variable & Coefficient & Std. Error & z-Statistic & Prob. \\
Const. & 2.546087 & 1.394663 & 1.825593 & 0.0679 \\
$y_{t-1}$ & 0.758581 & 0.080714 & 9.398428 & 0.0000 \\
$y_{t-3}$ & 0.166931 & 0.084206 & 1.982401 & 0.0474 \\
$x_{t}$ & $5.95 \times 10^{-5}$ & $2.48 \times 10^{-5}$ & 2.400805 & 0.0164 \\
$x_{t-1}$ & $8.73 \times 10^{-5}$ & $2.39 \times 10^{-5}$ & 3.659156 & 0.0003 \\
$x_{t-2}$ & 0.000121 & $2.87 \times 10^{-5}$ & 4.217008 & 0.0000 \\
$x_{t-3}$ & 0.000146 & $3.26 \times 10^{-5}$ & 4.473418 & 0.0000 \\
\hline
\end{tabular}

Results of variance equation as well as other statistics such as adjusted r-squared and model selection criteria are shown in Table 7:

Table 7. Results of variance equation and other criteria of running non-linear model 6.

\begin{tabular}{ccccc}
\hline C & 4.162009 & 3.129710 & 1.329839 & 0.1836 \\
RESID $(-1)^{\wedge} 2$ & 0.253625 & 0.100411 & 2.525865 & 0.0115 \\
GARCH(-1) & 0.667588 & 0.134890 & 4.949123 & 0.0000 \\
R-squared & 0.801205 & Mean dependent var & 37.26751 \\
Adjusted R-squared & 0.792805 & S.D. dependent var & 15.83317 \\
S.E. of regression & 7.207045 & Akaike info criterion & 6.625644 \\
Sum squared resid & 7375.694 & Schwarz criterion & 6.827251 \\
Log likelihood & -483.6105 & Hannan-Quinn criterion & 6.707554 \\
Durbin-Watson stat & 1.923084 & & \\
\hline
\end{tabular}

When the linear dependence between $X_{t}$ and its past values $X_{t-1}$ is of interest, the concept of correlation is changed to autocorrelation. Plots of calculated autocorrelation as well as partial autocorrelation of residuals and squared of residuals are shown in Figures 1 and 2, respectively:

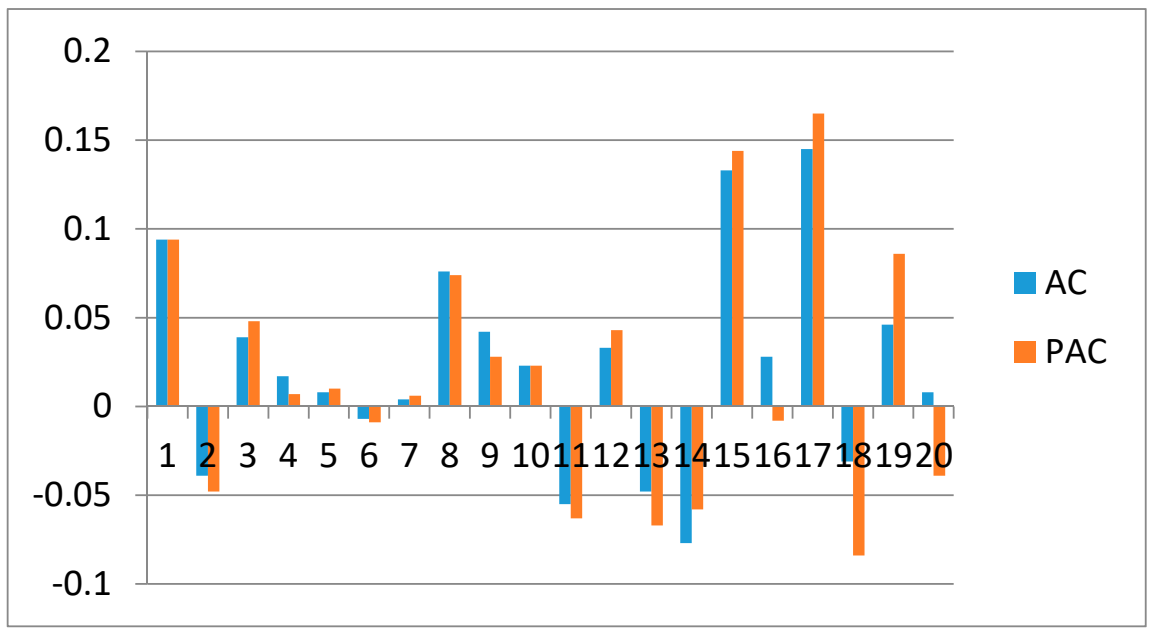

Figure 1. Correlogram of residuals. (The bar on left is autocorrelation (AC) and the bar on right is partial autocorrelation (PAC). An autocorrelation explains the strength of the relationship between past and current observations of a time series data. In a partial autocorrelation the effects of the intervening observation is removed.

The above figures show that there is no sign of autocorrelation or partial autocorrelation between residuals of our estimated model, which indicates that the estimated model is reliable. 
Several procedures are performed to test if the correlation coefficient is equal to zero. To show the robustness of our results using non-linear model (ARCH), we have also conducted the Quandt-Andrew single break point test using a liner model. The results are calculated based on Hansen's [32] method and are shown in Table 8. The null hypothesis of the Quandt-Andrew test is no breakpoint within fifteen percent trimmed data. Our overall results reject the null hypothesis of no breakpoint. That is, the use of linear model is not appropriate for examining the relationship between stock price and net income of GM.

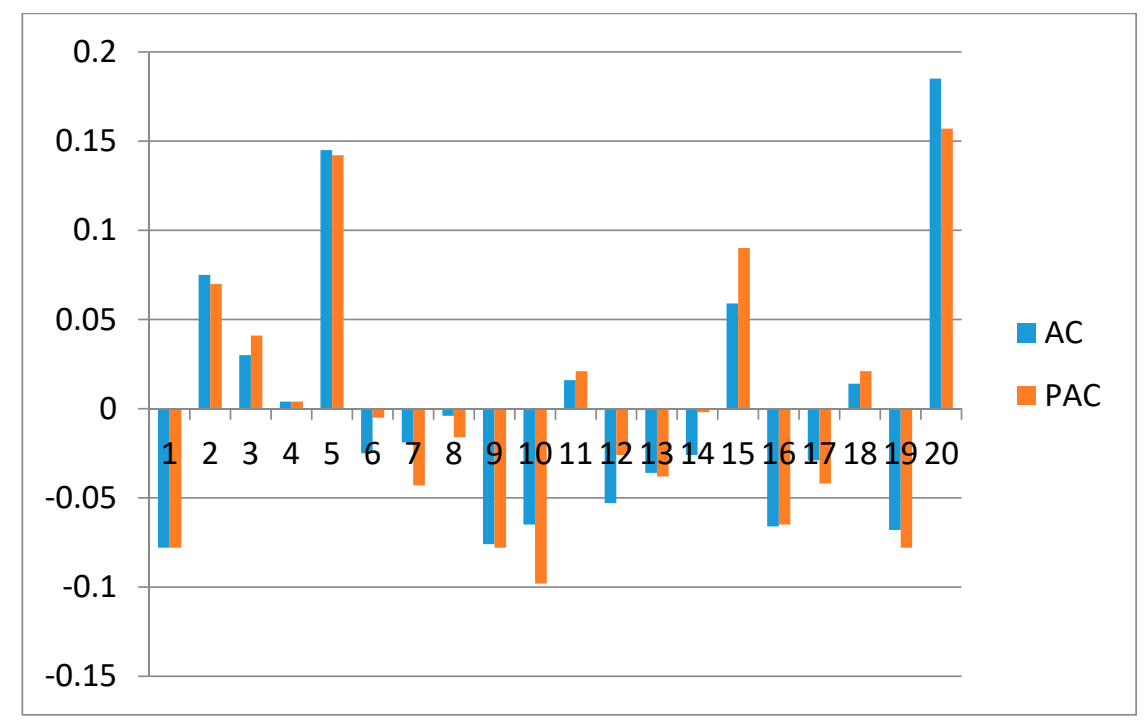

Figure 2. Correlogram of squared of residuals. (the bar on left is AC and the bar on right is PAC).

Table 8. Quandt-Andrews unknown breakpoint test.

\begin{tabular}{ccc}
\hline Statistic & Value & Prob. \\
\hline Maximum LR F-statistic (Obs. 128) & 3.715142 & 0.0118 \\
Maximum Wald F-statistic (Obs. 128) & 26.00599 & 0.0118 \\
Exp LR F-statistic & 0.606979 & 0.4870 \\
Exp Wald F-statistic & 9.012185 & 0.0185 \\
Ave LR F-statistic & 1.006934 & 0.4276 \\
Ave Wald F-statistic & 7.048538 & 0.4276 \\
\hline
\end{tabular}

Note: probabilities calculated using Hansen's [28] method.

The Maximum likelihood ratio (LR) statistics is used to compare two different maximum likelihood estimates of a parameter.

The Bai-Perron multiple breakpoints test is also conducted and the results are shown in Table 9:

Table 9. Bai-Perron tests of multiple breakpoints.

\begin{tabular}{|c|c|c|c|c|}
\hline \multicolumn{5}{|c|}{ Break Test Options: Trimming 0.15, Max. Breaks 5, Sig. Level 0.05} \\
\hline \multicolumn{4}{|c|}{ Sequential F-statistic determined breaks: } & 5 \\
\hline \multicolumn{4}{|c|}{ Significant F-statistic largest breaks: } & 5 \\
\hline \multicolumn{4}{|c|}{ UDmax determined breaks: } & 3 \\
\hline \multicolumn{4}{|c|}{ WDmax determined breaks: } & 4 \\
\hline & & Scaled & Weighted & Critical \\
\hline Breaks & F-statistic & F-statistic & F-statistic & Value \\
\hline $1 *$ & 3.715142 & 26.00599 & 26.00599 & 21.87 \\
\hline $2 *$ & 4.164864 & 29.15405 & 33.59321 & 18.98 \\
\hline $3 *$ & 5.086327 & 35.60429 & 45.19244 & 17.23 \\
\hline $4 *$ & 4.703992 & 32.92795 & 46.31088 & 15.55 \\
\hline $5 *$ & 3.826573 & 26.78601 & 43.71717 & 13.40 \\
\hline
\end{tabular}


Table 9. Cont.

\begin{tabular}{cccc}
\hline \multicolumn{5}{c}{ Break Test Options: Trimming 0.15, Max. Breaks 5, Sig. Level 0.05 } \\
\hline UDMax statistic * $^{*} 35.60429$ & UDMax critical value ** & 22.04 \\
WDMax statistic * $^{*}$ & 46.31088 & WDMax critical value ** & 23.81 \\
\multicolumn{5}{c}{ * Significant at the 0.05 level. } \\
** Bai-Perron critical values. \\
Estimated break dates: \\
1 & 128 & 96 & 128 \\
2 & 74 & 96 & 97 \\
3 & 74 & 75 & 97 \\
4 & 53 &
\end{tabular}

The UDmax and WDmax are procedure that test the null hypothesis of the existence of a zero break versus unknown number of breaks.

Consistent with the Qundt-Andrew single break point test, the Bai-Perron multiple break points test confirms the existence of multiple breakpoints, confirming that the use of non-linear ARCH mode is preferable to a linear model.

To test for the stability of the coefficients, we have conducted the Cumulative SUM control chart test (CUSUM test). The results are shown in Figure 3. Even though the diagram stays within the acceptable zone, it approaches the upper limit in one case. Figure 4 shows the behavior of the residuals of our estimated ARCH model. Figure 5 shows the actual, fitted and residuals of our estimated ARCH model. Finally, Figure 6 shows the actual, fitted, and residuals if we incorrectly used a linear model to fit our data. An ARCH model, or autoregressive conditional heteroskedasticity, is a statistical timeseries model that describes the variance of the current error terms as a function of the error terms in the previous period.

All of the above test results and figures confirm that the relationship between stock price $(Y)$ and net income $(\mathrm{X})$ of GM is non-linear, and the use of a linear model is inappropriate.

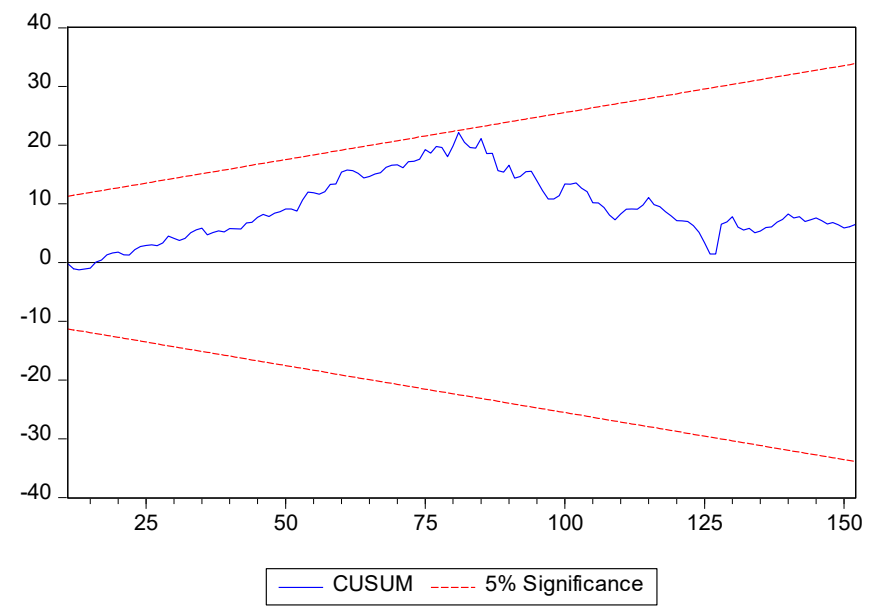

Figure 3. Results of CUSUM test. 


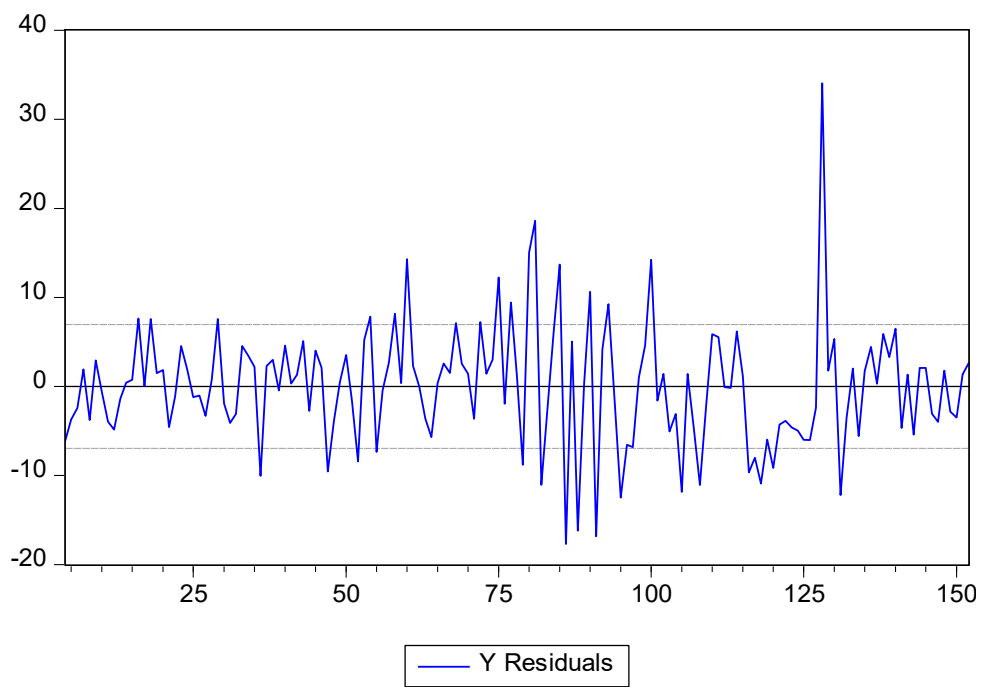

Figure 4. The behavior of the residuals of ARCH model.

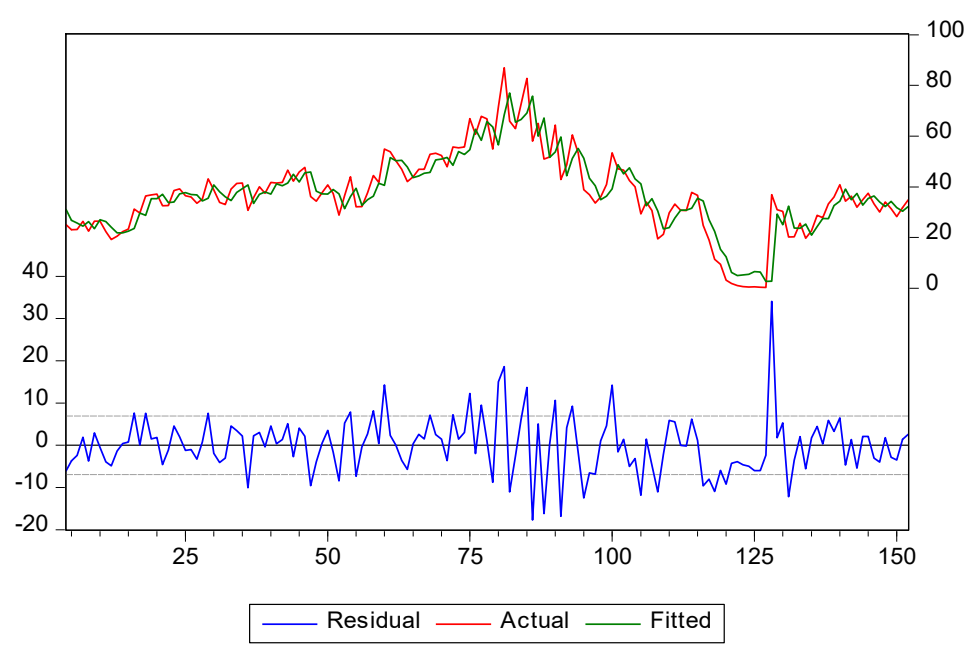

Figure 5. Actual, fitted and residuals of ARCH model. (top two curves are actual and fitted and the bottom one is residual).

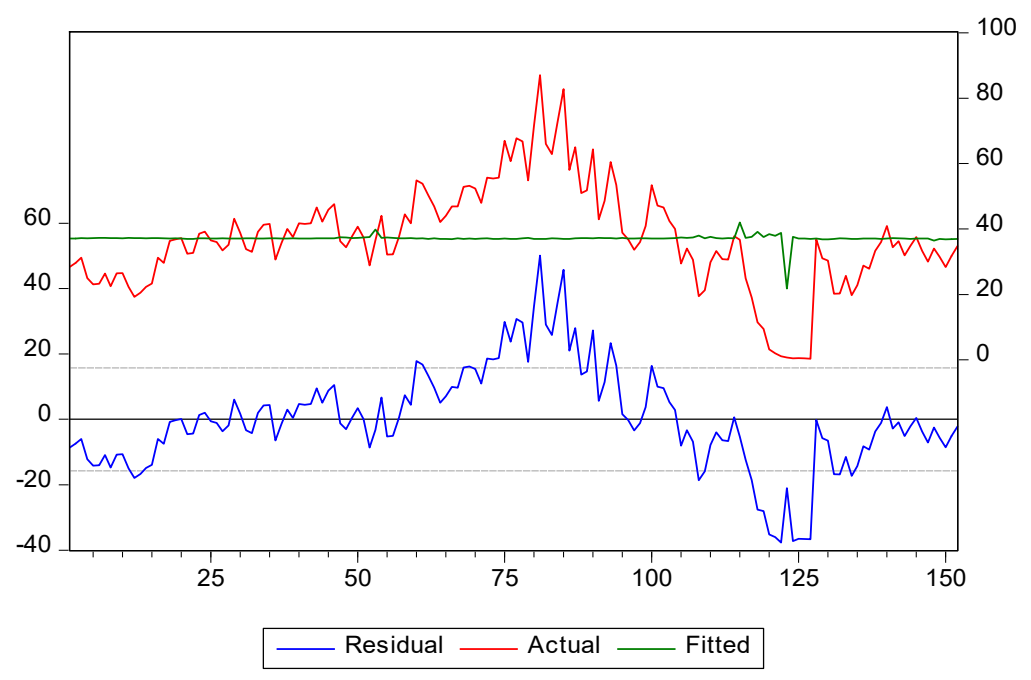

Figure 6. Actual, fitted and residuals of linear model. 


\subsection{Granger Causality}

The results of the pairwise Granger causality test (in the classical G-causality sense) are shown in Table 10. The null hypothesis of this test is that one variable does not cause change in the other variable. As the results show, we cannot reject the null hypothesis that stock price $(Y)$ does not cause change in net income $(X)$, but we reject the null hypothesis of net income $(X)$ does not cause change in stock price $(\mathrm{Y})$. In other words, we conclude that the previous observations of quarterly net income of GM can help to predict stock price of GM, but previous stock prices do not help us to predict quarterly net income of GM.

Table 10. Pairwise Granger causality tests.

\begin{tabular}{lrcc}
\hline Null Hypothesis: & Obs & F-Statistic & Prob. \\
\hline $\begin{array}{c}\text { X does not Granger } \\
\begin{array}{c}\text { cause Y } \\
\text { Y does not Granger cause X }\end{array}\end{array}$ & 147 & 5.79765 & $7 \times 10^{-5}$ \\
\hline
\end{tabular}

As we discussed earlier, the association reporting is an improvement over correlation reporting, and Granger causality reporting is an improvement over the association reporting.

\section{Policy, Practical, Education and Research Implications}

\subsection{Policy Implications}

The time series models presented in this study can be used by regulators, standard setting bodies, and policy makers in evaluating the efficiency and effectiveness of new standards and rules in the sense that economic consequences of new rules and standards be evaluated in terms of cost-benefit analyses and cause and effect with intended objectives. The intended consequences of rules, regulations and standards can be examined over time by using the time series models. We posit that the causation can be used by regulators in evaluating the effects of their proposed regulations and standards. The causation and association can help investors to better evaluate the pattern of data and detect unusual changes in bottom line information.

We posit that the time series models can be used by regulators in evaluating the financial statements of public companies. The Sarbanes-Oxley Act of 2002 requires that the Securities and Exchange Commission (SEC) review financial statements of public companies at least once every three years to prevent and detect fraud and irregularities. Time series models and analyses can be submitted as supplementary information through the SEC's Electronic Data Gathering and Retrieval (EDGAR) website. This supplementary information can help investors to better evaluate the pattern of data and detect unusual changes in bottom line information. Time series analyses are consistent with Section 408 of the Sarbanes-Oxley Act that requires the SEC to review annual financial statements of public companies to comply with the SEC rules and regulations. Lastly, time series analyses can be used by the Public Company Accounting Oversight Board (PCAOB) in inspecting annual financial statement audits.

Several organizations worldwide including the Global Reporting Initiative (GRI), International Integrated Reporting Council (IIRC), Sustainability Accounting Standard Board (SASB), and the United Nations Global Compact have issued guidelines regarding disclosure of non-financial environmental, social, and governance (ESG) sustainability performance information [33]. These organizations can use time series analyses presented in this paper in determining cause and effects of voluntary disclosure of ESG sustainability disclosure and the materiality benchmark that should be used in determining the type and extent of such disclosure. 


\subsection{Practical Implications}

Time series models and analyses can be used in practice for different purposes such as detecting symptoms of financial misstatements caused by errors fraud and irregularities. It is practical to use past data to build time series models for forecasting future events and financial earnings. These forecasts can then be compared with actual data to detect unusual fluctuations of data and investigate the variances (the differences between forecasted and actual data). Correlation, association, and special cases of causation can be used in practice for different purposes such as the determination of the link between non-financial ESG sustainability performance and financial performance. These types of comparisons are of interest to both public companies and their investors in developing hypotheses of the link between ESG sustainability and financial performance and then collecting data to support or reject their hypotheses. Hypotheses are developed by evaluating the pattern of past data together with the use of correlation, association, or Granger causality. In addition, time series information can be used in testing the causes and effects of sustainability disclosures.

The relationship between financial performance and ESG performance has been extensively yet inconclusively debated in the literature in the past decade, which has caused investors not to pay enough attention to sustainability factors of risk, performance, and disclosure [2,34]. However, a growing number of investors are now considering the impact of investing with a keen focus on financial return and ESG sustainability factors, regulators mandate ESG sustainability performance disclosure and public companies prepare and disseminate sustainability reports. In this era of sustainability-oriented investors, directors and executives, a major challenge is to show that ESG sustainability factors contribute to the bottom-line earnings and long-term return. Time series analyses can be used to demonstrate the causes and effects of the global move toward sustainability initiatives.

\subsection{Education Implications}

As discussed earlier in this paper, time series models and analyses are not adequately utilized and applied in business literature. Business schools and accounting programs can focus on the differences between correlation, association, and causation to ensure that these concepts are not used inappropriately and interchangeably. Educating students about these important topics are of great importance for courses that deal with budgeting, sustainability, and forecasting. We posit that the inadequate understanding of correlation, association, and causation is the result of unfamiliarity of accounting students with these important topics. Therefore, we recommend that business schools and accounting programs incorporate these topics into their related courses and better educate students in this regard.

We posit that underutilization of time series models in business is the result of unfamiliarity of academics, students, and practitioners with time series concepts. Even though time series courses are offered and taught in economics departments of many universities, usually as part of college of art and science, only a small number of business students take these courses because they are not classified as core courses, and it is not a common practice for business students to take these courses. Therefore, we recommend that business schools and accounting programs worldwide incorporate time series courses in their business and accounting curricula.

\subsection{Research Implications}

As discussed in the literature review of this paper, business researchers have not yet adequately used time series models and analyses in their studies. The common practice by business scholars is to use the traditional statistics in which they develop hypotheses, then collect data to test their hypotheses. However, in time series statistics, researchers collect data and investigate the pattern of data to generate hypotheses. The complexity of real-life activities and the high cost of using a cross-sectional approach and massive unobservable noises in the real life make the use of time series research more efficient and effective. We hope our study will open a window of opportunities for using time series concepts in 
business and, particularly, in the emerging opaque sustainability area where the link between financial economic performance and non-financial ESG sustainability performance is not well-established. To structure and effectively lead the business and sustainability research, we recommend that a framework and taxonomy for sustainability be developed to be used by researchers. We emphasize that the availability and expansion of public data have enabled the use of a time series approach in sustainability research in comparison with studies that use cross-sectional approach.

\section{Conclusions}

Time series models have been used in business research to transform unstructured and semi-structured data into structured information in improving the quality of financial and non-financial information. Researchers apply time series analyses in examining the value-relevance of non-financial ESG information and its link to financial and market performance. These studies often find mixed results of the relationship between financial economic sustainability performance information and non-financial ESG sustainability performance information because of the use of different time periods, variables definition and construction, hypothesis development and justification, and estimation methods. The quality and usefulness of sustainability studies could also improve by proper interpretation of results in terms of correlation, association, and causation. In this paper we discuss the differences between correlation, association, and Granger causality and their implications in business research. Business studies are often focused on the determination of the association between variables of interest and, thus, researchers examine the relationship between two variables while holding the effects of other related variables fixed (ceteris paribus). In science studies, researchers are able to examine the causation or the cause-effect relationship between two variables (e.g., smoking and cancers). For causation between $X$ and $Y$ in the direction from $X$ to $Y$ (for $X$ to cause $Y$ ) to hold, three conditions must be present: (1) $X$ and $Y$ must vary together, (2) $X$ must occur before $Y$ and (3) no other variables must cause change in $Y$ (when the effects of these other variables are controlled). These conditions are often challenging and difficult to hold in business research.

The difficulty of achieving a causal relationship between two variables encourage business researchers to consider a special case of causation called "the Granger causality" that focuses on using the past values of the first variable to predict the value of the second variable beyond the effects of past values of the second variable. We offer practical examples for correlation, association, and the Granger causality and discuss their main differences. We present analyses regarding the improvement from correlation (looking at movement of two variables without controlling the effects of other variables) to association (looking at movement of two variables after holding the effects other variables fixed), and to causation (what variables cause change in dependent variable). We conclude that because achieving causation is extremely difficult, the alternative is the use of Granger causality, which is the second best to causality. We show, using an empirical example, how the use of a linear regression may not be appropriate when the true relationship is not linear. Finally, we discuss the policy, practical, and educational implications of our paper. Academics conducting business sustainability research can use our suggested example in examining the possible link between financial economic sustainability performance and non-financial ESG sustainability performance, use time series analyses in detecting patterns in unstructured data, develop testable research hypotheses, and estimate association models that produce economically and statistically significant robust results.

Author Contributions: Conceptualization, Z.R.; methodology, A.D.; resources and data curation, S.A.; writing-original draft preparation, S.A., A.D., Z.R. and N.J.R.; writing-review editing and revision, N.J.R. and Z.R. All authors have read and agreed to the published version of the manuscript.

Funding: This research received no external funding.

Conflicts of Interest: The authors declare no conflict of interest. 


\section{References}

1. Huang, X.B.; Watson, L. Corporate social responsibility research in accounting. J. Account. Lit. 2015, 34, 1-16. [CrossRef]

2. Rezaee, Z. Business sustainability research: A theoretical and integrated perspective. J. Account. Lit. 2016, 36, 48-64. [CrossRef]

3. Stock, J.; Watson, M. Introduction to Econometrics, 3rd ed.; Addison-Wesley: Boston, MA, USA, 2011.

4. Haavelmo, T. The probability Approach in Econometrics (1944). Supplement to Econometrica 12 12\{17, 26\{31, 33\{39; Hendry, D.F., Morgan, M.S., Eds.; The Foundations of Econometric Analysis, Cambridge University Press: New York, NY, USA, 1995.

5. Pearl, J. Causal diagrams for empirical research. Biometrika 1995, 82, 23. [CrossRef]

6. Chen, B.; Pearl, J. Regression and Causation: A Critical Examination of Six Econometrics Textbooks. Real-World Econ. Rev. 2013, 65, 2-20.

7. Goldberger, A. Models of substance comment on N. Wermuth, On block-recursive linear regression equations. Braz. J. Probab. Stat. 1992, 6, 1-56.

8. Wermuth, N. On block-recursive regression equations. Braz. J. Probab. Stat. 1992, 6, 1-32.

9. Hill, R.; Griffiths, W.; Lim, G. Principles of Econometrics, 4th ed.; John Wiley \& Sons Inc.: New York, NY, USA, 2011.

10. Granger, C.W. Investigating Causal Relations by Econometric Models and Cross-spectral Methods. Econometrica 1969, 37, 424-438. [CrossRef]

11. Coval, J.; Hirshleifer, D.A.; Shumway, T. Can Individual Investors Beat the Market? Working Paper; Harvard University: Cambridge, MA, USA, 2005.

12. Bebchuk, L.; Cohen, A.; Ferrell, A. What Matters in Corporate Governance? The Harvard John M. Olin Discussion Paper Series: Electronic Copy. 2004. Available online: http://www.law.harvard.edu/programs/ olin_center/ (accessed on 19 September 2010).

13. Antonacci, G. Absolute Momentum: A Simple Rule-Based Strategy and Universal Trend-Following Overlay. Working Paper. Portfolio Management Consultants. 2013. Available online: http://optimalmomentum.com (accessed on 12 October 2015).

14. Cooper, T. Easy Volatility Investing. Working Paper. 2013. Available online: http://ssrn.com/abstract=2255327 (accessed on 15 August 2017).

15. Francis, A.; Mialon, M. A Diamond is Forever' and other Fairly Tales: The Relationship between Wedding Expenses and Marriage Duration. Econ. Inq. 2015, 53, 1919-1930. [CrossRef]

16. Becker, G.S.; Landes, E.M.; Michael, R. An Economic Analysis of Marital Instability. J. Political Econ. 1977, 85, 1141-1187. [CrossRef]

17. Conger, R.; Elder, D.G.H.; Lorenz, F.O.; Conger, K.J.; Simons, R.L.; Huck, W.H.; Melby, J.N. Linking Economic Hardship to Marital Quality and Instability. J. Marriage Fam. 1990, 52, 643-656. [CrossRef]

18. Bradbury, T.N.; Fincham, F.D.; Beach, S.R.H. Research on the Nature and Determinants of Marital Satisfaction: A Decade in Review. J. Marriage Fam. 2000, 62, 964-980. [CrossRef]

19. Charles, K.K.; Melvin, S., Jr. Job Displacement, Disability, and Divorce. J. Labor Econ. 2004, $22,489-522$. [CrossRef]

20. Dew, J.; Britt, J.; Huston, S. Examining the Relationship between Financial Issues and Divorce. Fam. Relat. 2012, 61, 615-628. [CrossRef]

21. Cevher, E. Causefinder: An R Package for Systemwise Analysis of Conditional and Partial Granger Causalities. Int. J. Sci. Adv. Technol. 2014, 4, 6-15.

22. Toda, H.Y.; Yamamoto, T. Statistical Inference in Vector Autoregressions with Possibly Integrated Processes. J. Econom. 1995, 66, 225-250. [CrossRef]

23. Boelstraete, B.; Roseel, Y. FIAR: An R Package for Analyzing Functional Integration in the Brain. J. Stat. Softw. 2011, 44, 1-32.

24. Guo, S.; Seth, A.K.; Kendrick, K.M.; Zhou, C.; Feng, J. Partial Granger causality—Eliminating exogenous inputs and latent variables. J. Neurosci. Methods 2008, 172, 79-93. [CrossRef]

25. Stokes, P.A.; Purdon, P.L. A Study of Problems Encountered in Granger Causality analysis from a Neuroscience Perspectives. Proc. Natl. Acad. Sci. USA 2018, 115, E6964. Available online: https://www.ncbi.nlm.nih.gov/ pmc/articles/PMC5576801/ (accessed on 18 July 2019). [CrossRef] 
26. Barnett, L.; Barrett, A.B.; Seth, A.K. Reply to Stokes and Purdon: A study of problems encountered in Granger causality analysis from a neuroscience perspective. arXiv 2017, arXiv:1708.08001.

27. Kendall, M.G. A new measure of rank correlation. Biometrika 1938, 30, 81-93. [CrossRef]

28. Pearson, K. Notes on regression and inheritance in the case of two parents. Proc. R. Soc. Lond. 1895, 58, 240-242.

29. Box, G.E.P.; Jenkins, G.M.; Reinsel, G.C. Time Series Analysis: Forecasting and Control; Prentice-Hall: London, UK, 1994.

30. Dickey, D.A.; Fuller, W.A. Distribution of the estimators for autoregressive time series with a unit root. J. Am. Stat. Assoc. 1979, 74, 427-431.

31. Tsay, R.S. Analysis of Financial Time Series, 2nd ed.; John Wiley \& Sons: Hoboken, NJ, USA, 2005.

32. Hansen, B.E. Approximate Asymptotic P-Values for Structural-Change Tests. J. Bus. Econ. Stat. 1995, 15, 60-67. [CrossRef]

33. Rezaee, Z.; Tsui, J.; Cheng, P.; Zhou, G. Business Sustainability in Asia: Compliance, Performance, and Integrated Reporting and Assurance; John Wiley: Hoboken, NJ, USA, 2019.

34. Rezaee, Z. Supply Chain Management and Business Sustainability Synergy: A Theoretical and Integrated Perspective. Sustain. J. 2018, 2018, 2-17.

(C) 2020 by the authors. Licensee MDPI, Basel, Switzerland. This article is an open access article distributed under the terms and conditions of the Creative Commons Attribution (CC BY) license (http://creativecommons.org/licenses/by/4.0/). 